\title{
Dietary fibre and sterol metabolism in the rat
}

\author{
By B. MORGAN, MONIQUE HEALD*, SANDRA D. ATKIN AND J. GREEN \\ Beecham Research Laboratories, Nutritional Research Centre, \\ Walton Oaks, Tadworth, Surrey
}

AND E. B. CHAIN

Department of Biochemistry, Imperial College of Science and Technology, London

$$
\text { (Received } 22 \text { fanuary I974-Accepted }{ }_{4} 4 \text { March 1974) }
$$

\footnotetext{
x. Sterol metabolism was studied in rats fed on a semi-synthetic fibre-free diet and in rats fed on diets containing cellulose $(2,00$ or $100 \mathrm{~g} / \mathrm{kg})$ or sugar-cane fibre (bagasse) at the same levels.

2. Rats fed on the diets containing cellulose or bagasse produced significantly greater quantities of faeces than did rats fed on the fibre-free diet.

3. Rats given bagasse excreted more bile acid and more neutral sterol in their faeces than did rats fed on cellulose or on the fibre-free diet.

4. After $28 \mathrm{~d}$, hepatic synthesis of cholesterol (from acetate) and cholesterol $7 \alpha$-hydroxylase activity were significantly higher in animals fed on bagasse than in animals fed on the other two diets.

5. No significant differences in serum cholesterol levels were seen in rats fed on any of the three diets.

6. Food consumption was not substantially altered by the inclusion of bagasse or cellulose in the diets, although the efficiency of foodstuff utilization was generally lower.

7. Bagasse adsorbed substantial quantities of cholic acid in vitro, whereas cellulose did not. The lignin fraction prepared from bagasse contributed only slightly to the total bile acid-binding capacity of bagasse.

8. The results are discussed in the light of possible effects of dietary fibre on sterol metabolism in man.
}

Recent epidemiological observations suggest that a deficiency of fibre in the diets of many modern populations may play an important role in the aetiology of certain so-called 'diseases of civilization' (Burkitt, I973). Of particular interest is the hypothesis, originally made by Walker \& Arvidsson (1954), that diets high in fibre are associated with relatively low serum cholesterol levels. The hypothesis was tested experimentally by Keys, Grande \& Anderson (196I), who gave dietary supplements of pure cellulose or pectin to human volunteers, and found a hypocholesterolaemic effect for the latter but not for the former. The epidemiological and experimental evidence for a relationship between dietary fibre, serum cholesterol and the incidence of occlusive vascular disease in human populations has been extensively reviewed by Trowell (1972). It was concluded that natural dietary fibre, which is a structured, heterogeneous mixture of celluloses, lignins and pectic substances, resistant to digestion by the human gastrointestinal tract, could differ in its effect from either pure cellulose or 'crude fibre' as defined analytically (Great Britain: Parliament, 1960).

A number of experiments on animals have indicated that certain foods high in

* Present address: Department of Nutritional Biochemistry, University of Surrey, Guildford, Surrey. 
Table I. Composition of experimental diets $(\mathrm{g} / \mathrm{kg})$ given to rats

\begin{tabular}{|c|c|c|c|c|c|}
\hline \multirow[b]{2}{*}{ Ingredient } & \multicolumn{5}{|c|}{ Diet } \\
\hline & A & B & $C$ & $D$ & E \\
\hline Vitamin-free casein & 200 & 200 & 200 & 200 & 200 \\
\hline Maize oil & 50 & 50 & 50 & 50 & 50 \\
\hline Minerals* & 28 & 28 & 28 & 28 & 28 \\
\hline $\mathrm{NaH}_{2} \mathrm{PO}_{4} \cdot 2 \mathrm{H}_{2} \mathrm{O}$ & 22 & 22 & 22 & 22 & 22 \\
\hline Vitamins* & 5 & 5 & 5 & 5 & 5 \\
\hline Glucose & 495 & 495 & 495 & 495 & 495 \\
\hline Maize starch & 200 & - & - & 100 & 100 \\
\hline Cellulose & - & - & 200 & - & 100 \\
\hline Bagasse & - & 200 & - & 100 & - \\
\hline
\end{tabular}

dietary fibre influence blood lipid levels and atheroma formation. The substances investigated include oats (Fisher \& Griminger, 1967), wheat straw (Moore, 1967), and stock laboratory diet (Kritchevsky \& Tepper, 1968). However, as noted by Cummings (1973), these studies were not designed primarily to investigate the role of fibre as a single component of the diet, and therefore it was difficult to distinguish any effect of fibre from that possibly exerted by changes in other dietary components.

We therefore decided to compare the effect of an isolated natural dietary fibre on sterol metabolism in the rat with that of cellulose. The dietary fibre used was bagasse, namely, that part of sugar cane remaining after the commercial extraction of all soluble carbohydrates; it has the advantage of being practically free of protein and lipids and is, like cellulose, almost entirely indigestible to the rat.

\section{MATERIALS AND METHODS}

Animals. Male rats of the CFY strain (Carworth Europe, Alconbury, Hunts.), initial body-weight $80-\mathrm{I00} \mathrm{g}$, were used. Animals were fed on a basal semi-synthetic fibre-free diet (Diet A) for Io d, after which they were allocated to experimental groups (sixteen rats/group, four rats/cage) so that the mean body-weight of each group was the same. The animals were given the experimental diets for 14 or $28 \mathrm{~d}$ and food and water were allowed ad lib. Body-weight and food consumption were recorded throughout the experimental period. Faeces were collected daily during days 8-I4 inclusive of each experiment, weighed, dried at $110^{\circ}$, ground in a laboratory mill and stored at $-\mathrm{r} 5^{\circ}$ for subsequent analysis. Samples from 3 consecutive days were pooled for bile-acid analysis, a single sample from each cage of rats being analysed in duplicate.

Diets. The composition of diets is shown in Table $\mathrm{I}$. The source of cellulose used was SolkaFloc BW-20 (Johnson, Jorgensen and Wettre Ltd, London).

Bagasse. The bagasse (a gift from Tate and Lyle Ltd, London) was ground in a laboratory hammer mill to a particle size similar to that of other constituents of the diets. Two grades, 'coarse' (ground to pass through a $2.5 \mathrm{~mm}$ diameter mesh) and 'fine' (ground to pass through a $0.7 \mathrm{~mm}$ diameter mesh) were used. 
We are indebted to Dr D. A. T. Southgate (Dunn Nutritional Laboratory, Cambridge) for the analysis of bagasse, which was as follows $(\mathrm{g} / \mathrm{kg})$ : moisture 72 , ash 19 , total nitrogen 2, pectic substances 5 , hemicelluloses $3^{\mathrm{I}} 3$ and cellulose plus lignin 492. Lignin was extracted from the bagasse as described by Eastwood \& Hamilton (r968) for wood lignin, to give a yield of $234 \mathrm{mg} / \mathrm{g}$ bagasse.

Biological measurements. Serum cholesterol was estimated by the Technicon Instruments Corporation (1967), as modified by Siegel \& Bowdoin (1971). The rate of digitonin-precipitable sterol biosynthesis from acetate, and cholesterol $7 \alpha$-hydroxylase activity were measured in liver slices according to the methods described by Atkin, Palmer, English, Morgan, Cawthorne \& Green (1972). Faecal bile acids were determined by gas-liquid chromatography of the methylated keto-bile-acid derivatives, as described by Evrard \& Janssen (1968). Faecal neutral sterols were estimated by the method of Miettinen, Ahrens \& Grundy (1965), except that sterols were separated from other lipids by thin-layer chromatography on plates of silica gel G, using chloroform as the developing solvent.

Binding of bile acids in vitro. The method used was based on that of Eastwood \& Hamilton ( 1968 ). Bagasse (fine grade), bagasse-lignin or cellulose ( $0.5 \mathrm{~g}$ each) was shaken at room temperature for $2.5 \mathrm{~h}$ in $10 \mathrm{ml} \mathrm{O} \cdot \mathrm{I} \mathrm{M}-\mathrm{NaH}_{2} \mathrm{PO}_{4} \cdot 2 \mathrm{H}_{2} \mathrm{O}-\mathrm{NaOH}$ buffer of varying $\mathrm{pH}$. The incubation mixture contained: $\mathrm{r} \cdot 5 \mathrm{mmol}$ sodium cholate plus a trace amount $(0.1 \mu \mathrm{Ci})$ of sodium $\left[24^{-14} \mathrm{C}\right]$ cholate (Radiochemical Centre, Amersham, Bucks.). After incubation, the mixtures were filtered and the radioactivity in the filtrates was determined using an Intertechnique ABAC SL 40 spectrometer (Intertechnique Ltd, Portslade, Sussex), corrected for quenching using the external standard channels-ratio method. The scintillation fluid consisted of $6 \mathrm{~g}$ 5-(4-biphenylyl)-2(4-t-butylphenyl)-I-oxa-3,4-diazole dissolved in I 1 toluene-Triton X-10o $(2: \mathrm{I}, \mathrm{v} / \mathrm{v})$ (Patterson \& Greene, 1965).

Statistical analysis. Statistical analyses were done using Student's $t$ test or, when small numbers of samples were involved, the U statistic of Mann \& Whitney (1947).

\section{EXPERIMENTAL AND RESULTS}

\section{Expt I}

In an initial experiment, diets containing $200 \mathrm{~g}$ bagasse (coarse grade) or cellulose $/ \mathrm{kg}$ were used, in addition to a diet containing $100 \mathrm{~g}$ bagasse (coarse grade) $/ \mathrm{kg}$. The experimental diets were given for $28 \mathrm{~d}$. The results of Expt $\mathrm{I}$ are given in Table 2. In addition to the measurements described previously, energy intake and digestible energy were estimated, using a ballistic bomb calorimeter (Gallenkamp, London).

It is clear that the inclusion of either bagasse or cellulose in the diets led to a large and significant increase in faecal output, this increase being accounted for by solid material rather than by any marked change in moisture content. The increase in faecal output was of the same order in animals fed on equivalent amounts of bagasse or cellulose (diets $B$ and $C$ ); the animals fed on $100 \mathrm{~g}$ bagasse $/ \mathrm{kg} \operatorname{diet}(\operatorname{diet} \mathrm{D}$ ) produced a weight of faeces intermediate between animals fed on the fibre-free diet (diet A) and on high-fibre diets ( $B$ and $C$ ). The increase in faecal weight could be accounted for 


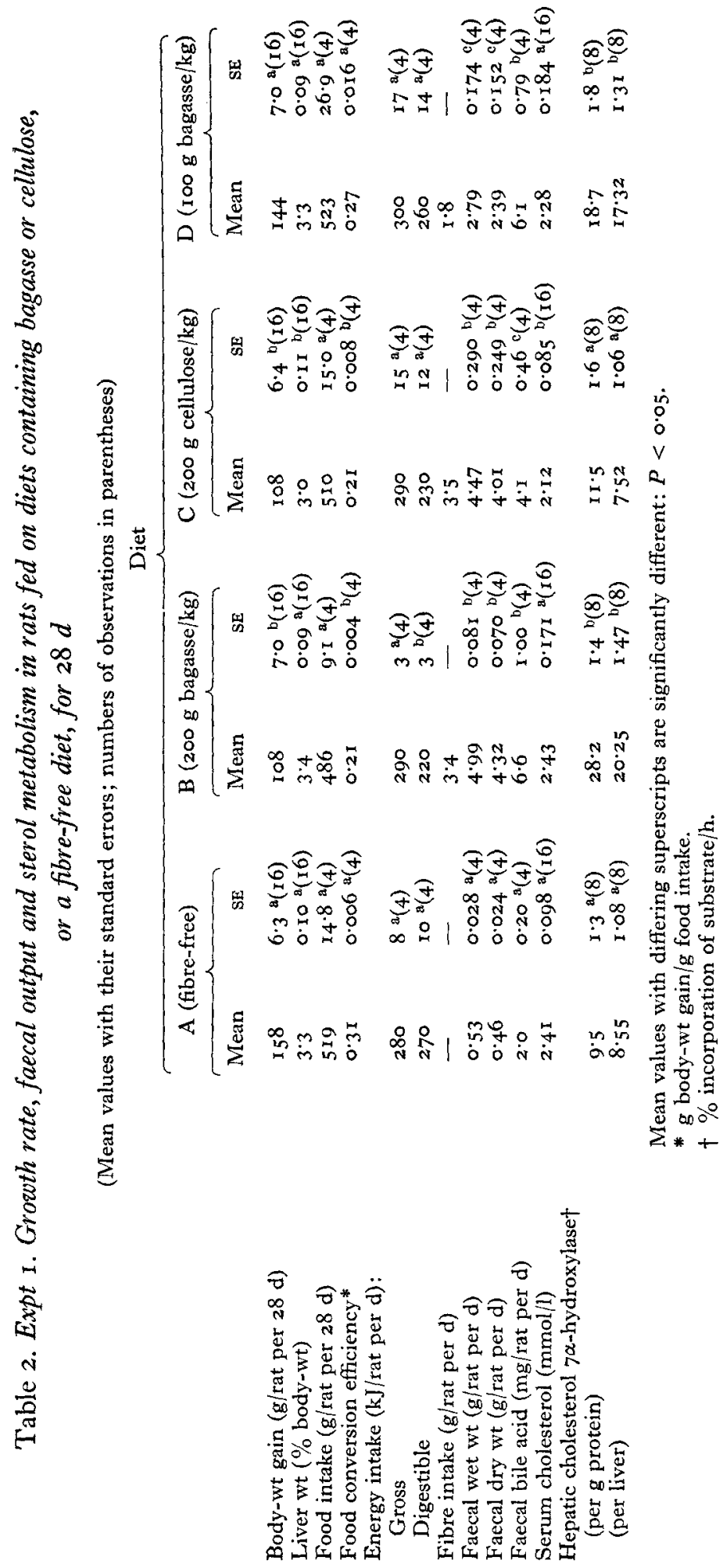


almost entirely by the bagasse or cellulose consumed by the animals, thus confirming that both these substances are virtually indigestible. The output of total faecal bile acids was increased in groups B, C and D compared to that of group A. However, the animals fed on bagasse at either 100 or $200 \mathrm{~g} / \mathrm{kg}$ diet excreted significantly more bile acids than did animals fed on the diet containing $200 \mathrm{~g}$ cellulose $/ \mathrm{kg}$.

It is known that an increased faecal bile acid output is often reflected in an increase in hepatic bile acid biosynthesis. For example, rats given the bile acid sequestering agent cholestyramine show this phenomenon (Boyd, Scholan \& Mitton, I969). It has been shown that the rate-limiting enzyme in the conversion of cholesterol to bile acids in the liver is cholesterol $7 \alpha$-hydroxylase (Danielsson, Einarsson \& Johansson, 1967). We therefore measured this enzyme and found a significant increase in the animals fed on both levels of bagasse, but none in animals fed on cellulose.

It is interesting to note that food consumption during the experimental period did not differ markedly between the four groups of rats. Body-weight gain in the animals in groups $\mathrm{B}$ and $\mathrm{C}$, therefore, was lower than that in animals fed on the fibre-free diet. This is reflected in the reduced efficiency of food utilization shown in the fibre-fed animals. Gross energy intake did not differ between animals fed on fibre-free or fibrecontaining diets. However, digestible energy in animals fed on diets $\mathrm{B}$ or $\mathrm{C}$ was lower than that in animals fed on the fibre-free diet, the difference between groups $A$ and $B$ being statistically significant.

\section{Expt 2}

In this experiment diets containing $100 \mathrm{~g}$ bagasse (fine or coarse grade) $/ \mathrm{kg}$ were used. The experiment was designed to investigate $(a)$ the effect of giving fibre for $14 \mathrm{~d}$ and $(b)$ the effect of bagasse of different particle size. The results are shown in Table 3.

Although some differences in body-weight gain and food consumption between groups were observed, no consistent picture emerged. Faecal weight was again significantly increased to a similar degree by both grades of bagasse, and also by cellulose. As in Expt $\mathrm{r}$, giving the bagasse and cellulose diets resulted in each instance in a significant rise in faecal bile acid. Again, output produced by both grades of bagasse was significantly greater than that produced by cellulose. However, the increase in cholesterol $7 \alpha$-hydroxylase observed after $28 \mathrm{~d}$ in Expt I was not found in any group after $14 \mathrm{~d}$.

In addition to the measurements of Expt $\mathrm{I}$, hepatic sterol biosynthesis from acetate was measured. It would be expected that this would be increased as a result of an enhanced bile acid production (see Discussion). However, no such increase was observed in this experiment with animals fed on bagasse and, indeed, animals fed on cellulose showed a markedly reduced level of sterol synthesis. The observation is difficult to explain and is discussed later. No differences in serum cholesterol levels were found.

\section{Expt 3}

This experiment extended the studies of Expt 2 for $28 \mathrm{~d}$. Since no important differences were observed between the two grades of bagasse in Expt 2, fine grade bagasse only was used in Expt 3. The results are given in Table 4.

The effects of bagasse and cellulose on faecal weight and faecal bile acid were 


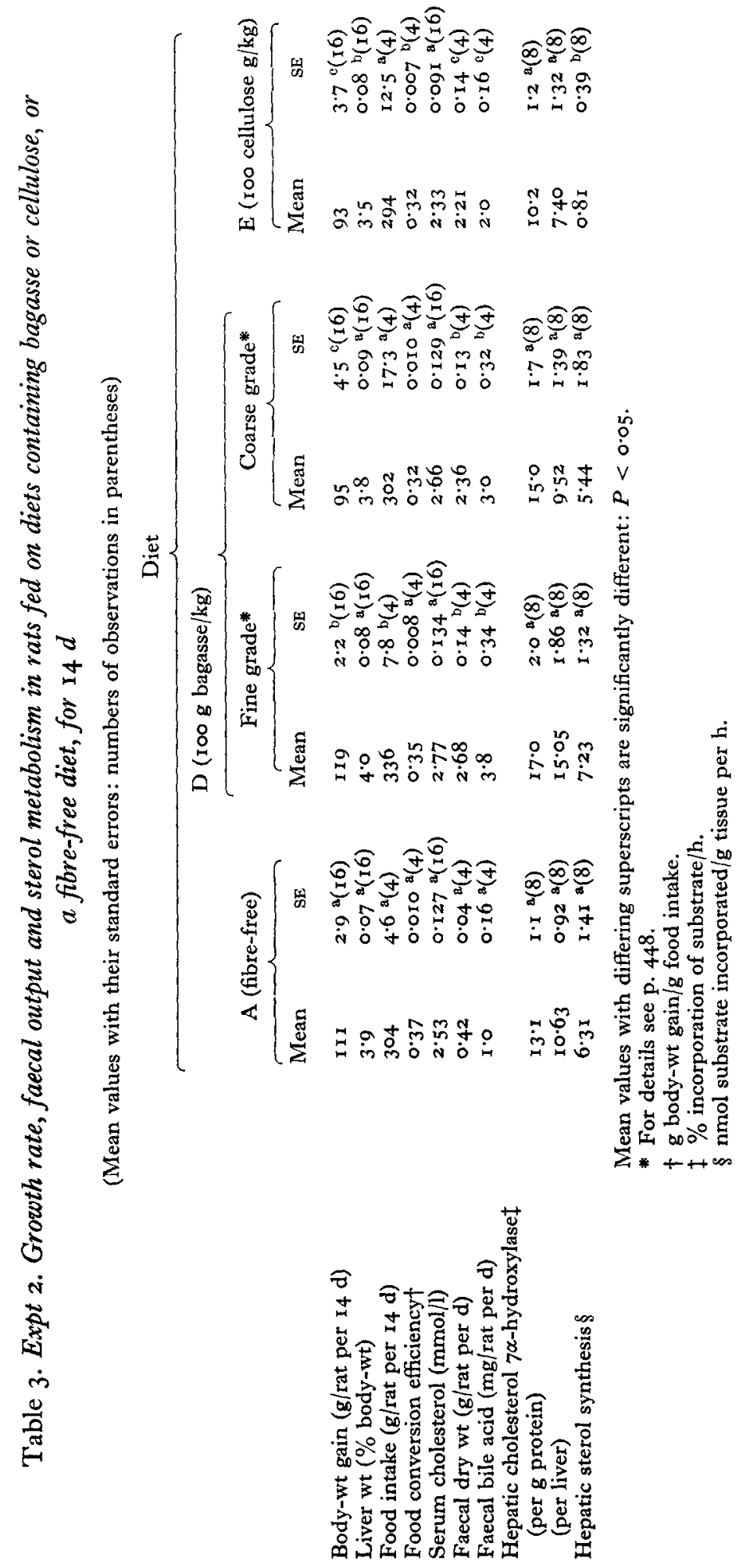


Table 4. Expt 3. Growth rate, faecal output and sterol metabolism in rats fed on diets containing bagasse or cellulose, or a fibre-free diet, for $28 d$

(Mean values with their standard errors; numbers of observations in parentheses)

Body-wt gain (g/rat per $28 \mathrm{~d}$ )

Liver wt ( $\%$ body-wt)

Food intake (g/rat per $28 \mathrm{~d}$ )

Food conversion efficiencyt

Serum cholesterol (mmol/1)

Faecal wet wt (g/rat per d)

Faecal dry wt (g/rat per d)

Faecal bile acid (mg/rat per d)

Faecal neutral sterol (mg/rat per d)

Hepatic cholesterol $7 \alpha$-hydroxylase $\ddagger$ (per g protein)

(per liver)

Hepatic sterol synthesis $\S$
Diet

\begin{tabular}{|c|c|c|c|c|c|}
\hline \multicolumn{2}{|c|}{ A (fibre-free) } & \multicolumn{2}{|c|}{$\begin{array}{c}\mathrm{D}(100 \mathrm{~g} \\
\text { bagasse } / \mathrm{kg})^{*}\end{array}$} & \multicolumn{2}{|c|}{$\begin{array}{c}\mathrm{E}(\mathrm{r} 00 \mathrm{~g} \\
\text { cellulose } / \mathrm{kg})\end{array}$} \\
\hline Mean & $\mathrm{SE}$ & Mean & SE & Mean & SE \\
\hline 145 & $6 \cdot 1{ }^{a}(16)$ & I54 & I $8.9^{a}(I 6)$ & I I 6 & $8.6^{b}(16)$ \\
\hline $3 \cdot 5$ & $0.09 \mathrm{a}(16)$ & 34 & $0.08 a(I 6)$ & $3 \cdot x$ & $0.06^{b}(\mathrm{x} 6)$ \\
\hline 480 & $18 \cdot 3^{\circ}(4)$ & 503 & $12 \cdot 4^{a}(4)$ & 460 & $23.4^{b}(4)$ \\
\hline 0.30 & $0.007^{a}(4)$ & 0.27 & $0.013^{a}(4)$ & 0.24 & $0.01 \ln ^{b}(4)$ \\
\hline $2 \cdot 35$ & $0.085^{2}(x 6)$ & $2 \cdot 17$ & $0.096^{a}(\mathrm{I} 6)$ & $2 \cdot 35$ & $0.083^{2}(16)$ \\
\hline $0.4 \mathrm{I}$ & $0.02^{2}(4)$ & $2 \cdot 33$ & $0.09^{b}(4)$ & 1.92 & $0.06^{c}(4)$ \\
\hline 0.35 & $0.01^{10}(4)$ & $1 \cdot 93$ & $0.02 b(4)$ & $1 \cdot 69$ & $0.07^{c}(4)$ \\
\hline 0.7 & $0.13^{a}(4)$ & $3 \cdot 3$ & $0.19^{b}(4)$ & $2 \cdot 3$ & $0.26^{c}(4)$ \\
\hline $2 \cdot 34$ & $0.24^{2}(4)$ & $3 \cdot 37$ & $0.12^{b}(4)$ & 3.09 & $0.32^{a}(4)$ \\
\hline $10 \cdot 8$ & $0.9^{2}(9)$ & $17 \cdot 7$ & $2 \cdot I^{b}(10)$ & $I I \cdot 2$ & $2 \cdot 0 \mathrm{a}(10)$ \\
\hline $\begin{array}{r}13 \cdot 72 \\
2 \cdot 21\end{array}$ & $\begin{array}{l}x \cdot 44^{a}(9) \\
0.64^{a}(9)\end{array}$ & $\begin{array}{r}2 I \cdot 53 \\
6.05\end{array}$ & $\begin{array}{l}3.26^{b}(10) \\
0.18^{b}(10)\end{array}$ & $\begin{array}{r}10.45 \\
0.61\end{array}$ & $\begin{array}{l}1.72^{a}(10) \\
0.25^{c}(10)\end{array}$ \\
\hline
\end{tabular}

Mean values with differing superscripts are significantly different: $P<0.05$.

* Containing 'fine grade' bagasse, see p. 448 .

$+\mathrm{g}$ body-wt gain/g food intake.

$\ddagger \%$ incorporation of substrate/h.

$\S \mathrm{nmol}$ substrate incorporated/g tissue per $\mathrm{h}$.

confirmed. As previously observed, although dietary cellulose was associated with increased faecal weight to the same extent as when the animals were given bagasse, faecal bile-acid output in rats fed on bagasse was significantly higher than that in rats fed on cellulose. It was also confirmed (cf. Expt $\mathrm{I}$ ) that feeding with bagasse for $28 \mathrm{~d}$ resulted in a significant increase in cholesterol $7 \alpha$-hydroxylase, whereas feeding with cellulose caused no increase. Faecal neutral sterols (cholesterol plus coprostanol) were also measured in this experiment and animals fed on bagasse produced more faecal sterol than did animals fed on either cellulose or on the fibre-free diet. Hepatic sterol synthesis was markedly increased by bagasse, but the unexpected reduction of synthesis in cellulose-fed animals seen in Expt 2 was again observed. No significant changes in serum cholesterol levels were found.

\section{Binding of bile acid in vitro}

Bagasse (fine grade), bagasse lignin and cellulose were examined for their capacity to bind cholic acid in vitro. The results are shown in Table 5. Whole bagasse adsorbed appreciable quantities of cholate, the adsorption being similar throughout the $\mathrm{pH}$ range tested. Bagasse lignin also adsorbed an appreciable amount of bile acid. However, equal weights of bagasse and bagasse lignin were used. Therefore, as bagasse contains approximately $230 \mathrm{mg}$ lignin/g, the cholic acid-binding capacity of the lignin contributes to a minor degree only to the total capacity of bagasse as a whole. Cellulose was found to have only a low capacity for binding cholic acid under the conditions of this experiment. 
Table 5. Binding of sodium cholate by bagasse, bagasse-lignin and cellulose in vitro*

Percentage of sodium cholate adsorbed at $\mathrm{pH}$ :

$r_{6.0} \quad 7_{8.0} \quad 9.0$

Bagasse (fine grade)

Bagasse-lignin

$47 \cdot 6$

$18 \cdot 9$

$36 \cdot 5$

$35 \cdot 2$

$4 I \cdot 7$

Cellulose

$5 \cdot 4$

$19 \cdot 8$

$22 \cdot 8$

$29 \cdot 3$

* For conditions see p. 449 .

DISCUSSION

We have demonstrated that, in the rat, feeding with a diet high in a natural heterogeneous non-available dietary fibre (bagasse) resulted in significant alterations of sterol metabolism when compared to feeding with a fibre-free diet or a diet containing an equal amount of cellulose. These changes occurred although, in our experiments, the faecal bulk-promoting properties of both bagasse and cellulose were similar.

The hepatic synthesis of both cholesterol and bile acids is controlled by a complex system of negative feedback (reviewed by Dietschy \& Wilson, I970a, $b$ ). It is thought that the rate of synthesis of cholesterol is probably kept in a repressed state by cholesterol returning to the liver via the entero-hepatic circulation, and that cholesterol catabolism to bile acids is likewise controlled either by cholesterol or by bile acids returning from the gut. An enhancement of bile-acid excretion effectively reduces the quantity of both bile acids and cholesterol (bile acids being required for the absorption of cholesterol) returning to the liver. Therefore, in these circumstances, both cholesterol synthesis and catabolism are no longer subject to as much feedback control as under normal conditions and the result may be a compensatory increase in both cholesterol and bile-acid synthesis. In man, it is thought that the increase in synthesis of cholesterol arising from enhanced bile-acid excretion cannot fully compensate for the increased catabolism to bile acids and the total body pool of cholesterol therefore decreases, causing a fall in serum cholesterol levels. In the rat, however, the compensatory mechanism is more efficient and the body pool of cholesterol is maintained. Serum cholesterol levels in the rat therefore do not normally decrease even when bile acid excretion is enhanced, as, for example, in rats given cholestyramine (Gallo, Harkins, Sheffner, Sarett \& Cox, 1966). We have demonstrated that, in rats fed with bagasse, bile-acid biosynthesis, as reflected by changes in the rate-limiting enzyme, cholesterol $7 \alpha$-hydroxylase, was indeed increased in response to the increase in faecal bile acid, as was hepatic synthesis of cholesterol from acetate. However, these changes were not immediate and were observed at $28 \mathrm{~d}$ but not at $\mathrm{I} 4 \mathrm{~d}$. In contrast, the feeding of cellulose produced the changes to a minor degree or not at all. In fact, animals fed on cellulose showed a remarkably low level of hepatic synthesis of cholesterol. We are unable to offer any explanation for this and subsequent experiments (Morgan, Heald, Atkin, Green \& Chain, unpublished results) did not consistently show the effect.

Our experiments in vitro indicate that the biological effects of bagasse can be attributed, at least in part, to the capacity of this substance to adsorb bile acids. It has 
been previously suggested that lignins are capable of binding bile acids in the gut (Eastwood \& Girdwood, 1968). However, we found that a lignin preparation from bagasse only contributed to a minor degree to the binding properties of the material as a whole. Heaton, Heaton \& Barry (197I) found that lignin had no effect on bile-acid excretion in man.

Our results suggest, therefore, that dietary bagasse affects sterol metabolism by mechanisms that are not entirely attributable to its faecal bulk-promoting property, such as is possessed by cellulose. In man, such a property could conceivably, in the long-term, contribute to a lowering of serum cholesterol and could be relevant when considering dietary effects in relation to the aetiology of atherosclerosis. Furthermore, the clearly demonstrated metabolic effect on sterol catabolism could indirectly affect the absorption and metabolism of other nutrients and non-nutrients.

We thank Mrs C. R. Chard, Mrs C. M. Bell, Mr C. Driscoll and Miss B. E. Lowe for technical assistance, $\mathrm{Mr} \mathrm{B}$. Bashford for gas-liquid chromatographic analyses and Mr D. Hiley and Mrs E. Evans for care of the animals.

\section{REFERENCES}

Atkin, S. D., Palmer, E. D., English, P. D., Morgan, B., Cawthorne, M. A. \& Green, J. (1972). Biochem. 7. $128,237$.

Boyd, G. S., Scholan, N. A. \& Mitton, J. R. (1969). Adv. exp. Med. Biol. 4, 443.

Burkitt, D. P. (1973). Br. med. F. i, 274 .

Cummings, J. H. (1973). Gut $\mathbf{x}_{4}, 69$.

Danielsson, H., Einarsson, K. \& Johansson, G. (1967). Eur. F. Biochem. 2, 44.

Dietschy, J. M. \& Wilson, J. D. (1970a). New Engl. Э. Med. 282, 1128.

Dietschy, J. M. \& Wilson, J. D. (1970b). New Engl. F. Med. 282, 1241.

Diplock, A. T., Green, J., Bunyan, J., McHale, D. \& Muthy, I. R. (1967). Br. F. Nutr. 2x, I1 5.

Eastwood, M. A. \& Girdwood, R. H. (1968). Lancet ii, Ir7o.

Eastwood, M. A. \& Hamilton, D. (1968). Biochim. biophys. Acta 152, I65.

Evrard, E. \& Janssen, G. (I968). F. Lipid Res. 9, 226.

Fisher, H. \& Griminger, P. (1967). Proc. Soc. exp. Biol. Med. x26, 108.

Gallo, D. G., Harkins, R. W., Sheffner, A. L., Sarett, H. P. \& Cox, W. M. Jr (I966). Proc. Soc. exp. Biol. Med. 122, 328.

Great Britain: Parliament (1960). Stat. Instrum. no. I 165.

Heaton, K. W., Heaton, S. T. \& Barry, R. E. (1971). Scand. F. Gastroenterol. 6, 3.

Keys, A., Grande, F. \& Anderson, J. T. (1961). Proc. Soc. exp. Biol. Med. ro6, 555.

Kritchevsky, D. \& Tepper, S. A. (1968). F. Atheroscler. Res. 8, 357.

Mann, H. B. \& Whitney, D. R. (1947). Ann. math. Statist. 18, 52 .

Miettinen, T. A., Ahrens, E. H. Jr \& Grundy, S. M. (1965). F. Lipid Res. 6, $4 \mathrm{rr}$.

Moore, J. H. (1967). Br. F. Nutr. 21, 207.

Patterson, M. S. \& Greene, R. C. (1965). Analyt. Chem. 37, 854 .

Siegel, A. L. \& Bowdoin, B. C. (1971). Clin. Chem. 17, 229.

Technicon Instruments Corporation (1967). Technical Bulletin N-24a. Tarrytown, New York: Technicon Instruments Corp.

Trowell, H. C. (1972). Am. F. clin. Nutr. 25, 926.

Walker, A. R. P. \& Arvidsson, U. B. (1954). F. clin. Invest. 33, 1358. 